\title{
Prediction and Controlling of Flyrock due to Blasting for Kyaukpahto Gold Mine
}

\author{
Myo Min Lwin ${ }^{1}$ and Zaw Moon Aung ${ }^{2}$ \\ Professor ${ }^{1}$ and Demostrator ${ }^{2}$ \\ ${ }^{1-2}$ Department of Mining Engineering \\ Mandalay Technological University, Mandalay Division, Mandalay \\ Myanmar
}

\begin{abstract}
This paper presents the prediction of maximum flyrock distances due to blasting for Kyaukpahto Gold Mine. Flyrock is an unwanted throw of rock fragments during bench blasting in mines. Flyrock is one of the major undesirable effects of blasting for the surface mines because it is the main cause of fatal accidents and serious injuries. The aim of this study is to control the flyrock impacts due to blasting and the estimation of safe distances. In this paper, important and widely used empirical formulae have been used to predict the maximum flyrock distance for the Kyaukpahto Gold Mine. To select the optimum flyrock distance formula, maximum throw distance empirical formulae analysis were carried out by using the data of Kyaukpahto Gold Mine. Moreover, an excel program is used for the analysis. The paper concludes with the guidelines for applying the maximum flyrock distances based on the various rock types (sandstone, dolomite, and granite), amount of charges per delay and burden distances in Myanmar surface mines.
\end{abstract}

Key Words: Maximum Flyrock Distance, Kyaukpahto Gold Mine, Prediction, Safe Distance, Amount of Charge per Delay.

\section{INTRODUCTION}

Flyrock is the source of most of the injuries and property damage in a majority of blasting accidents in surface mines. Flyrock refers to the uncontrolled dispersion of rock fragments from blast areas caused by explosive energy. Flyrock may cause damage to structures and injury to human. Therefore, flyrock prediction is required to determine safe blasting zone.

The control of flyrock within secured distance around the blasting site can largely be established by proper selection of various blast design parameters. Selection of proper burden plays the most crucial role, as blasts with very small or very large burden may be associated with excessive flyrock. The powder factor is another important parameter, which influences the generation of flyrock. The precision in drilling is very important in controlling the flyrock, because even small errors in drilling may result in substantial increase in the powder factor, which may aggravate the flyrock problem.

There are generally three flyrock mechanisms, cratering, rifling and face burst, which are defined upon the origin of the flyrock fragments. Cratering is the result of insufficient stemming height so that flyrock comes from the crater formed around the blasthole collar. Rifling is a result of insufficient or absent stemming so that stemming material or rock fragments are propelled through the blasthole upwards. Face burst is a result of weakened and faulted zones in the bench face. [1]

In Myanmar, there are many metal/quarry mines for mining industry. With the general trend toward large blasts in metal mine projects, vibration and flyrock problems and complaints have also increased. Consequently, lawsuit cases have developed between the mining industry and the general public at an accelerating rate. The objective of this paper is to provide a method of determining the relationship between throw of fragments and blast design based on data obtained in the field. In this paper, the maximum flyrock distances are predicted by using the empirical formulae and excel program for the Kyaukpahto Gold Mine.

\section{METHODS FOR PREDICTION OF MAXIMUM FLYROCK DISTANCE}

There are several empirical methods to predict maximum flyrock distance by various researchers. One single predictor equation cannot fully satisfy all the variation in the observation field data. In this paper, the following five empirical formulae are used to predict the maximum flyrock distance. 
International Journal of Advances in Scientific Research and Engineering (ijasre), Vol 5 (10), October-2019

\subsection{Lundborg et al. Equation (1975)}

Lundborg et al. developed the co-relation to estimate the maximum distance (Lmax) of flyrock from the blasthole diameter (D), as:

$\mathrm{L}_{\max }=30.745 \mathrm{D}^{0.66}$

where, $\operatorname{Lmax}=$ Maximum flyrock distance, $\operatorname{meters}(\mathrm{m})$

$\mathrm{D}=$ Blasthole diameter, millimeters $(\mathrm{mm})$. [4]

\subsection{Lundborg et al. Equation (1981)}

The maximum flyrock distance, for a specific charge $>0.2 \mathrm{~kg} / \mathrm{m}^{3}$ may be estimated from the following equation:

$\mathrm{L}_{\max }=143 \times \mathrm{d} \times(\mathrm{q}-0.2)$

where, $\mathrm{L}_{\max }=$ Maximum throw $(\mathrm{m})$

$\mathrm{d}=$ Hole diameter (ins)

$\mathrm{q}=$ Specific charge $\left(\mathrm{kg} / \mathrm{m}^{3}\right)$. [6]

\subsection{Chiapetta et al. Equation (1983)}

The maximum flyrock distance can be calculated by the following formula. Air resistance, wind direction and speed are neglected.

$\mathrm{R} 1=\mathrm{V}_{0} \mathrm{x}(2 \sin 2 \theta) / \mathrm{g}$

$\mathrm{V}_{0}=(10 \mathrm{~d} \times 2600) /(\mathrm{Tb} \times \rho r)$

$\mathrm{Tb}=0.1 \mathrm{~d}^{2 / 3}$

where, $\mathrm{R} 1$ is distance travelled $(\mathrm{m})$ by the rock along a horizontal line at the original elevation of the rock on the face, $\mathrm{V}_{0}$ is initial velocity of the flyrock, $\theta$ is the angle of departure with the horizontal, and $\mathrm{g}$ is gravitational constant, $\mathrm{d}$ is hole diameter in inch, $\mathrm{Tb}$ is size of rock fragment $(\mathrm{m})$, and $\rho r$ is density of rock in $\mathrm{g} / \mathrm{cm}^{3}$. [2]

\subsection{Gupta Equation (1990)}

Gupta established an empirical relation amongst stemming length, burden and flying distance of projectiles, as given below:

$\mathrm{L}=155.2 \times \mathrm{D}^{-1.37}$

where $\mathrm{L}=$ Ratio of length of stemming column to burden (1s/B)

$\mathrm{D}=$ Distance travelled by the flying fragments in meters. [2]

\subsection{Terrock Equation (2005)}

The flyrock model developed by Terrock for face burst:

$\mathrm{L}=\left(\mathrm{k}^{2} / 9.8\right)\left(\frac{\sqrt{m}}{B}\right)^{2.6} \mathrm{x} \sin 2 \theta$

where, $\mathrm{L}$ is maximum throw $(\mathrm{m}), \mathrm{m}$ is charge mass per delay $(\mathrm{kg}), \mathrm{B}$ is burden $(\mathrm{m}), \theta$ is launch angle from horizontal (45 degree) , $\mathrm{k}$ is 13.5 for soft competent rock, 27 for hard competent rock. [5]

\section{CAUSES OF FLYROCK}

There are numerous factors which determine the blast area:

1) Geology or material to be blasted

2) Blast pattern

3) Burden, depth, diameter and angle of hole.

4) Blasting experience of mining personnel.

5) Delay system, powder factor and pounds per delay.

6) Type and amount of explosive material.

7) Type and amount of stemming.

Generally fly rocks are caused due to mis-match of ex-plosive energy with the geo-mechanical strength of the rock mass surrounding the explosive charge. Factors responsible for such mis-match are discussed below:

Burden: An insufficient burden is a primary cause of flyrock from a high wall face. Problems related to burden causing flyrock:

1) Too short a distance to the bench slope wastes energy.

2) Too great a burden distance causes improper fracturing of rock, creating oversize boulders and potential of Fly-rock for next round.

3) Due to irregularity of bench slope. 
Blast Hole Loading: Blast hole over charging is one of the frequent causes of the fly rock occurrence. Such overloading generates excessive release of energy. It happens due to loss powder in fissure, joints voids and cracks. In order to prevent overloading, it is necessary to load holes as designed using the correct charge weight. Additionally, a blast stemming should be sufficiently high to eliminate the possibility of excessive charging and holes have to be monitored to check the rise of the explosives.

Stemming: Stemming materials provide confine-ment and prevent the escape of high pressure gases from blasting holes. This material must be free from rocks and properly tamped. Inadequate stemming results in stemming ejection from the holes resulting in flyrocks.

Geology and Rock Structure: The rock structure and rock properties vary considerably from location to location even within the same blast area. Problems encountered here are:

1) Discontinuity in geology and rock structure causes a mismatch between explosive energy and resistance of rock.

2) Existence of fissures, joints, weakness and voids are likely to assist in the generation of flyrock.

3) Changing compressive strength, varying abrasiveness and rock density also create hazardous scenario.

Detonator Fining Delay: Critical elements of any blast design are firing delays between adjacent holes in a row. Proper firing delay helps to achieve good fragmentation. Rock fragmented by previous hole must be given chance to move prior to firing the subsequent holes.

Blasthole Pattern: Inaccuracies in the design of blasting pattern, including large deviation from planned pattern results in flyrock occurrences. The causes of improper blast design include:

1) Insufficient explosive confinement

2) Inadequate burden

3) Short stemming region or failure to use stemming

4) High powder factor for the given rock conditions

5) Improper delay between rows

6) Incorrect blast hole delay sequence

7) Inappropriate location of front row holes

8) Top initiation while using the conventional system of detonating fuse

9) Occurrence of misfires during the blasting

Carelessness: Unfortunately, carelessness in drill-ing and blasting is a leading cause of excessive fly rock and carelessness during any part of:

1) The blast design

2) The blast hole pattern layout

3) The drilling of the blast holes

4) The loading of explosives

5) The hook-up of the initiation system

Blast Supervision: Generally, the poor blast site control is the major cause of accidents due to fly rock in the surface mines. [3]

\section{INFORMATION OF THE PROJECT}

The project of Kyaukpahto Gold Mine is located about six miles east of Kyauktan village and 13 miles from Kawlin Township in Sagaing Division. For the research, field data collects from this project are expressed in Table 1.

Table 1. Information of the project

\begin{tabular}{|l|l|l|}
\hline 1 & Type of rock & Sandstone \\
\hline 2 & Daily production & 1500 tons \\
\hline 3 & Type of explosive & Emulsion \\
\hline 4 & Bench height & $7 \mathrm{~m}$ \\
\hline 5 & Drill hole diameter & $64 \mathrm{~mm}$ \\
\hline 6 & Drill hole incline & 10 degree \\
\hline 7 & Stemming length & $2.45 \mathrm{~m}$ \\
\hline 8 & Burden distance & $2.45 \mathrm{~m}$ \\
\hline 9 & Spacing & $2.92 \mathrm{~m}$ \\
\hline 10 & Loading density & $3.46 \mathrm{~kg} / \mathrm{m}$ \\
\hline 11 & Explosive amount & $18.5 \mathrm{~kg} / \mathrm{hole}$ \\
\hline 12 & Specific charge & $0.37 \mathrm{~kg} / \mathrm{m}^{3}$ \\
\hline 13 & Delay & 6 holes per delay \\
\hline
\end{tabular}




\section{ANALYSIS WITH EMPIRICAL FORMULA}

In this paper, a comparative analysis between the results obtained by using the data of Kyaukpahto Gold Mine project to select the optimum empirical formula. In the Lundborg et al. Equation (1975), drill hole diameters are considered to predict the maximum flyrock distance. Table 2 and figure 1 show the relationship of drill hole diameters and flyrock distances.

Table 2. The relationship of drill hole diameters and flyrock distances

\begin{tabular}{|c|c|}
\hline Drill hole diameter(mm) & Flyrock Distance $(\mathrm{m})$ \\
\hline 51.00 & 411.88 \\
\hline 64.00 & 478.47 \\
\hline 76.00 & 535.93 \\
\hline 89.00 & 594.80 \\
\hline 102.00 & 650.80 \\
\hline 110.00 & 684.06 \\
\hline 115.00 & 704.43 \\
\hline 127.00 & 752.12 \\
\hline 152.00 & 846.82 \\
\hline 178.00 & 939.84 \\
\hline
\end{tabular}

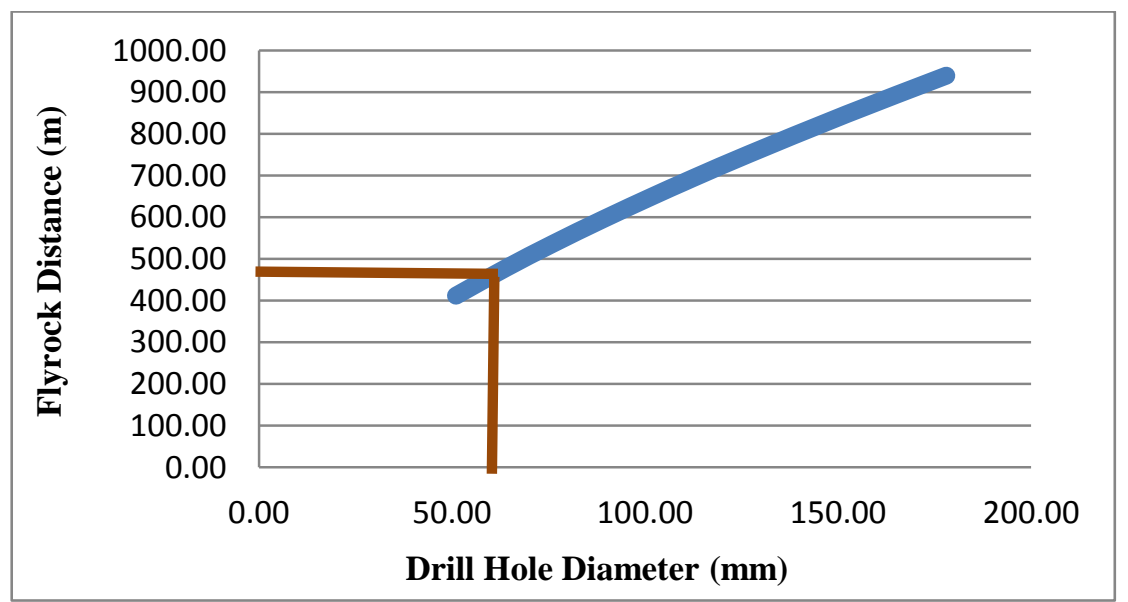

Figure 1. The relationship of the drill hole diameters and maximum flyrock distances

According to the results, the maximum flyrock distance is $478.47 \mathrm{~m}$ for the Kyaukpahto Gold Mine. In the Lundborg et al. Equation (1981), drill hole diameter and specific charge are considered to estimate the maximum flyrock distances. Table 3 and figure 2 show the results of the maximum flyrock distances by using the field data.

Table 3. The results of the flyrock distance

\begin{tabular}{|c|c|c|c|c|c|c|c|}
\hline $\begin{array}{c}\text { Drill hole diameter } \\
\text { (in) }\end{array}$ & 0.3 & 0.37 & 0.4 & 0.45 & 0.5 & 0.6 & 0.7 \\
\hline 2 & 29 & 49 & 57 & 72 & 86 & 114 & 143 \\
\hline 2.5 & 36 & 61 & 72 & 89 & 107 & 143 & 179 \\
\hline 3 & 43 & 73 & 86 & 107 & 129 & 172 & 215 \\
\hline 3.5 & 50 & 85 & 100 & 125 & 150 & 200 & 250 \\
\hline 4 & 57 & 97 & 114 & 143 & 172 & 229 & 286 \\
\hline 4.25 & 61 & 103 & 122 & 152 & 182 & 243 & 304 \\
\hline 4.5 & 64 & 109 & 129 & 161 & 193 & 257 & 322 \\
\hline 5 & 72 & 122 & 143 & 179 & 215 & 286 & 358 \\
\hline 6 & 86 & 146 & 172 & 215 & 257 & 343 & 429 \\
\hline 7 & 100 & 170 & 200 & 250 & 300 & 400 & 501 \\
\hline
\end{tabular}




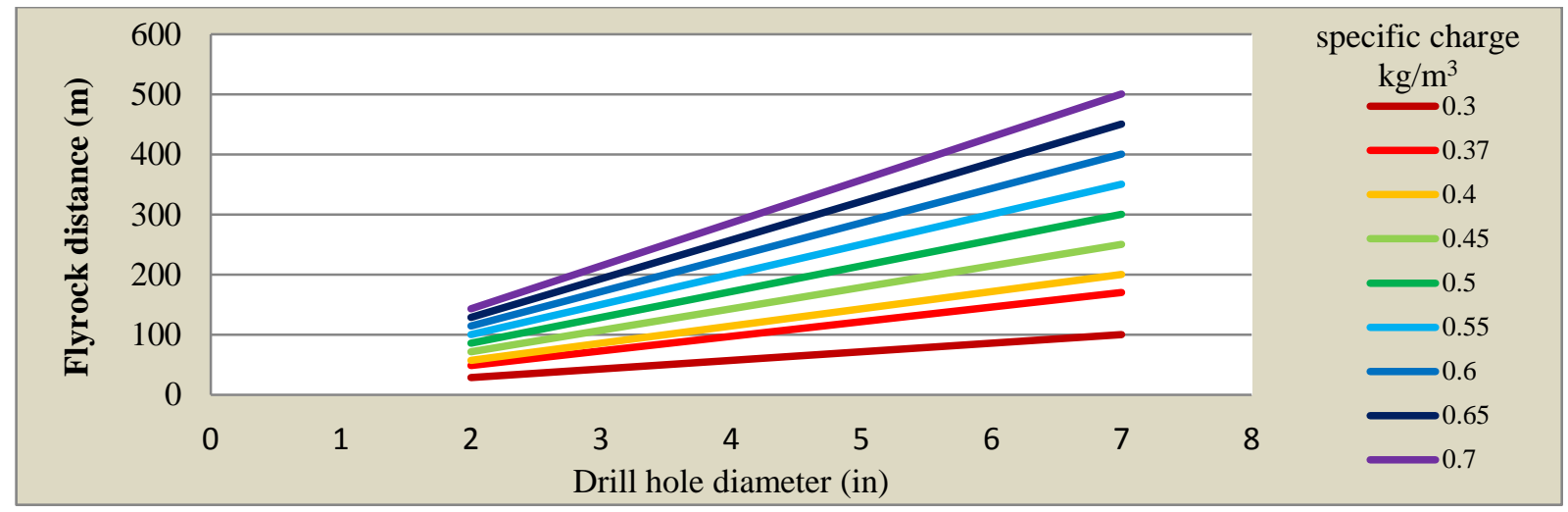

Figure 2. The results of the flyrock distances depend on the drill hole diameter and specific charge

In the project, 2.5 in drill hole diameter and $0.37 \mathrm{~kg} / \mathrm{m}^{3}$ specific charge are used for the production design. According to the result, the maximum flyrock distance for the project is $61 \mathrm{~m}$.

In the Chiapetta et al. Equation (1983), drill hole diameter and rock density are considered to predict the maximum flyrock distance. Table 4 and figure 3 show the result of flyrock distances by using the Chiapetta et al. equation.

Table 4. The maximum flyrock distance

\begin{tabular}{|c|c|c|c|c|c|c|}
\hline \multirow{2}{*}{$\begin{array}{c}\text { Drill hole diameter } \\
\text { (in) }\end{array}$} & Sandstone & Limestone & Granite & Dolomite & Slate & Marble \\
\cline { 2 - 7 } & 1.85 & 1.94 & 2.19 & 2.36 & 2.28 & 2.02 \\
\hline 2 & 354 & 337 & 299 & 277 & 287 & 324 \\
\hline 2.5 & 381 & 364 & 322 & 299 & 309 & 349 \\
\hline 3 & 405 & 386 & 342 & 318 & 329 & 371 \\
\hline 3.5 & 427 & 407 & 360 & 334 & 346 & 391 \\
\hline 4 & 446 & 4259 & 377 & 350 & 362 & 409 \\
\hline 4.25 & 455 & 434 & 385 & 357 & 369 & 417 \\
\hline 4.5 & 464 & 443 & 392 & 364 & 376 & 425 \\
\hline 5 & 481 & 458 & 406 & 377 & 390 & 440 \\
\hline 6 & 511 & 487 & 432 & 400 & 414 & 468 \\
\hline 7 & 538 & 513 & 454 & 422 & 436 & 493 \\
\hline
\end{tabular}

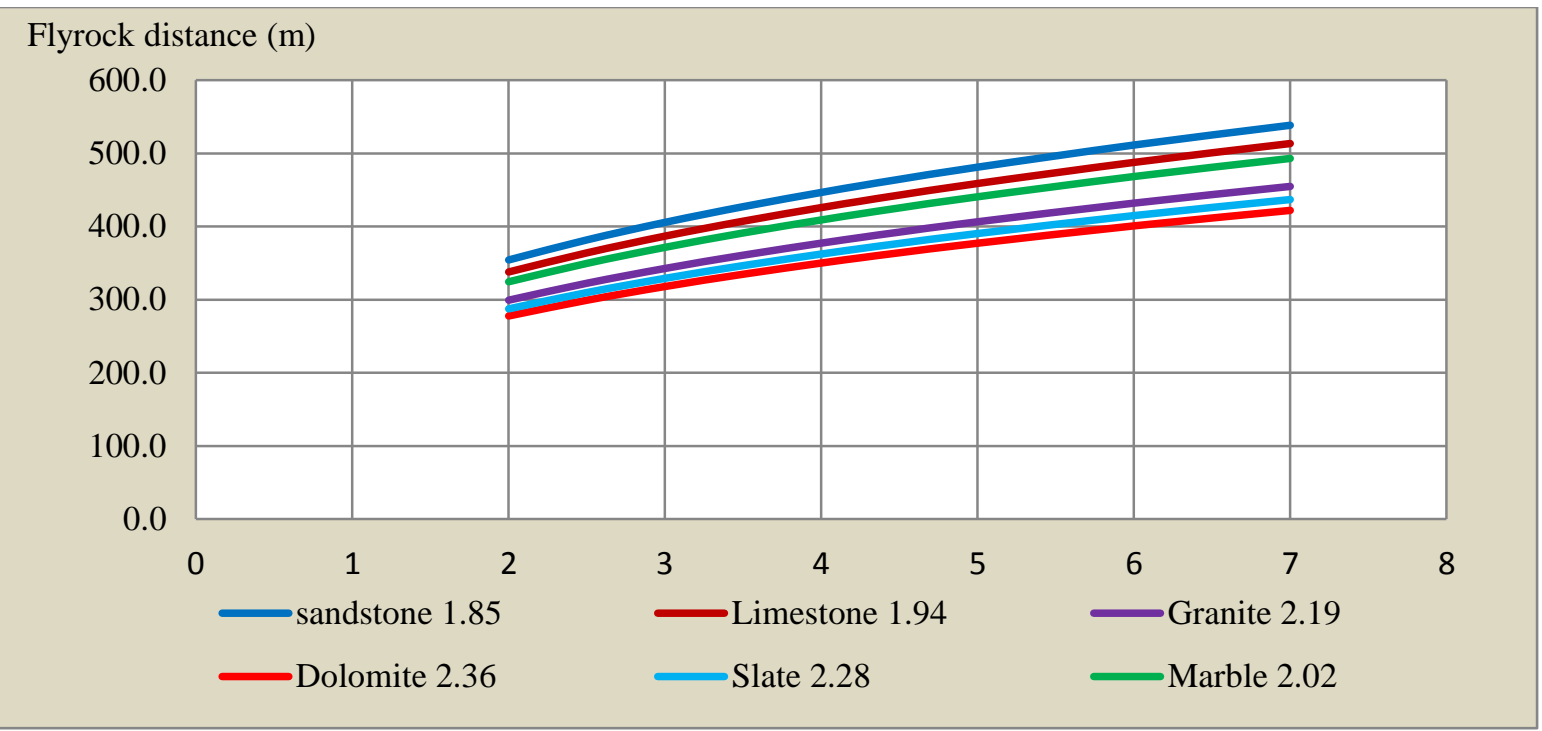

Figure 3. The result of the maximum flyrock distances depend on the rock density and drill hole diameter

According to the results of equation, the maximum flyrock distance is $381 \mathrm{~m}$. In the project, rock type is sandstone and drill hole diameter is $2.5 \mathrm{in}$. To estimate the maximum flyrock distance, the ratio of stemming length and burden distance is main factor in the Gupta (1990) equation. Table 5 and figure 4 show the results of maximum flyrock distance. 
International Journal of Advances in Scientific Research and Engineering (ijasre), Vol 5 (10), October-2019

Table 5. The relationship of stemming length /burden distance and flyrock distance

\begin{tabular}{|c|c|}
\hline Stemming length/Burden distance & Flyrock Distance $(\mathrm{m})$ \\
\hline 0.1 & 1132.85 \\
\hline 0.2 & 566.42 \\
\hline 0.3 & 377.62 \\
\hline 0.4 & 283.21 \\
\hline 0.5 & 226.57 \\
\hline 0.6 & 188.81 \\
\hline 0.7 & 161.84 \\
\hline 0.8 & 141.61 \\
\hline 0.9 & 125.87 \\
\hline 1 & 113.28 \\
\hline 1.1 & 102.99 \\
\hline 1.2 & 94.40 \\
\hline 1.3 & 87.14 \\
\hline 1.4 & 80.92 \\
\hline 1.5 & 75.52 \\
\hline 1.6 & 70.80 \\
\hline 1.7 & 66.64 \\
\hline 1.8 & 62.94 \\
\hline 1.9 & 59.62 \\
\hline 2 & 56.64 \\
\hline & \\
\hline & \\
\hline
\end{tabular}

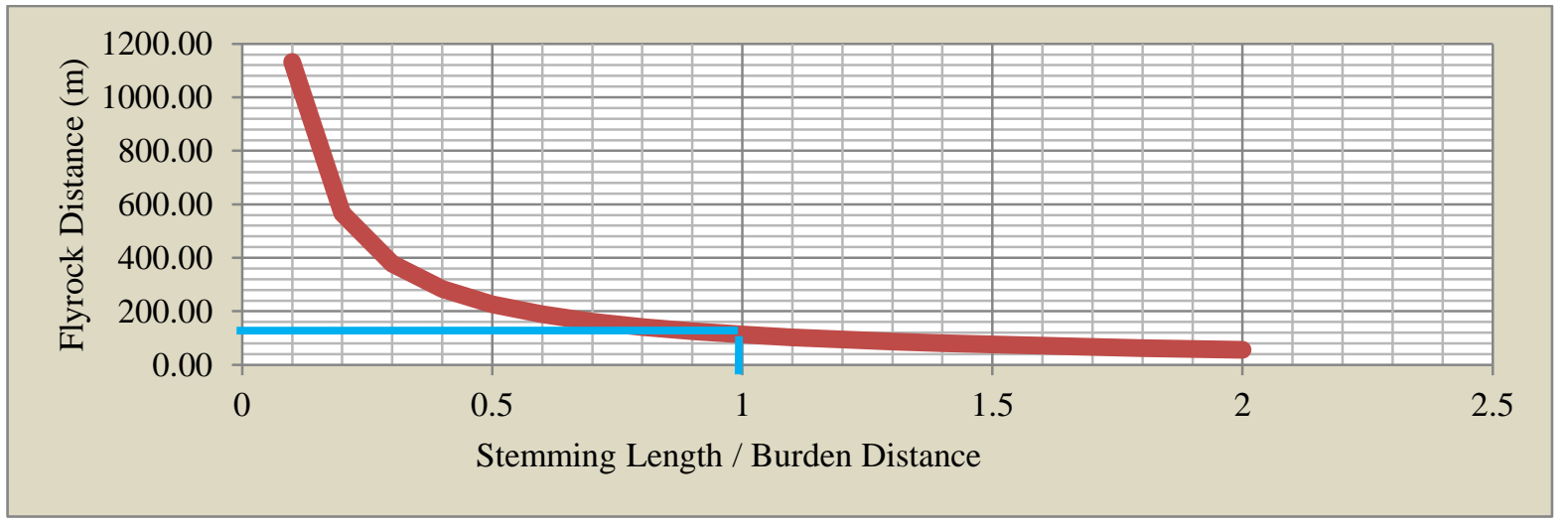

Figure 4. The results of the maximum fly rock distances depend on the ratio of stemming length and burden distance

According to the results, the maximum flyrock distance for the project is $113.28 \mathrm{~m}$. The ratio of the stemming length and burden distance of project is 1 .

In the Terrock equation (2005), charge mass per delay, burden distance and drill hole angle are considered to estimate the maximum flyrock distance. Table 6 and figure 5 show the results of maximum flyrock distances.

Table 6. The relationship of the charge per delay and flyrock distance

\begin{tabular}{|c|c|}
\hline Charge per delay $(\mathrm{kg})$ & Flyrock distance $(\mathrm{m})$ \\
\hline 18.5 & 80.34 \\
\hline 37 & 197.82 \\
\hline 55.5 & 335.11 \\
\hline 74 & 487.09 \\
\hline 92.5 & 651.02 \\
\hline 111 & 825.14 \\
\hline 129.5 & 1008.23 \\
\hline 148 & 1199.36 \\
\hline 166.5 & 1397.81 \\
\hline 185 & 1603.00 \\
\hline
\end{tabular}


International Journal of Advances in Scientific Research and Engineering (ijasre), Vol 5 (10), October-2019

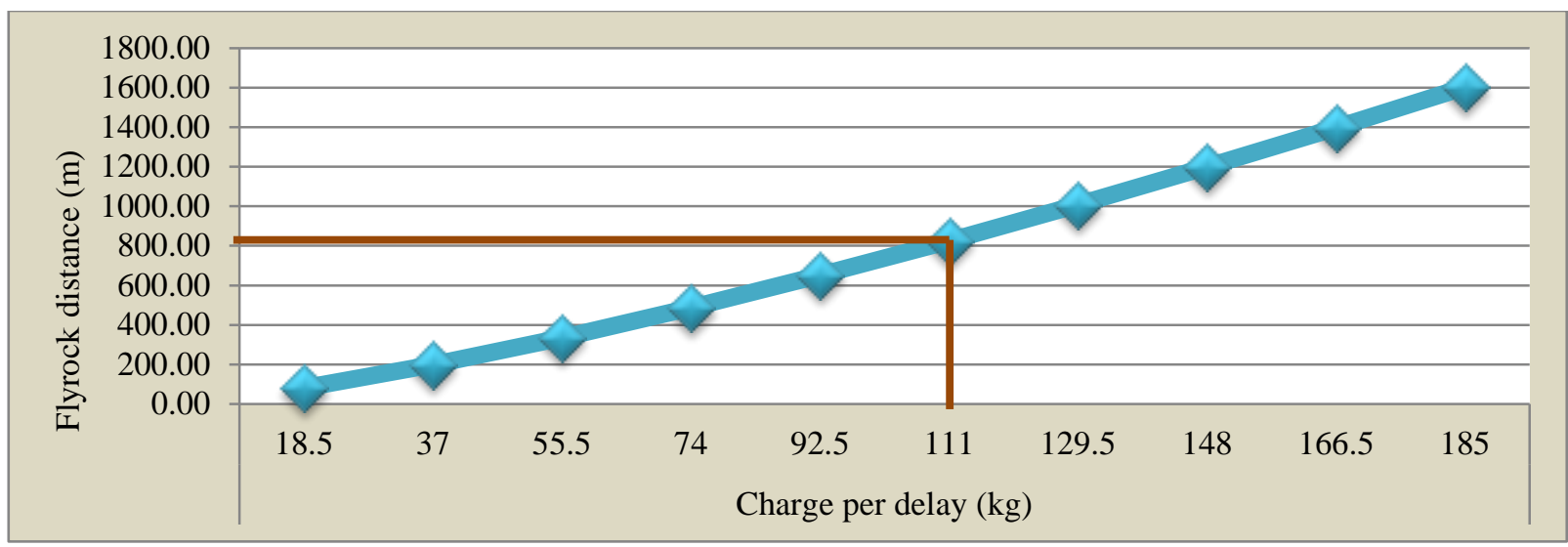

Figure 5. The relationship of charge per delay and flyrock distances

In the Kyaukpahto Gold Mine, six holes per delay are used to control the blasting impacts. So, the maximum flyrock distance is $825.14 \mathrm{~m}$. Figure 6 shows the results of maximum flyrock distances for Kyaukpahto Gold Mine.

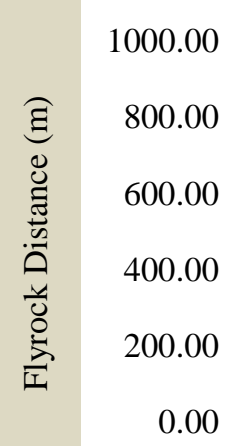
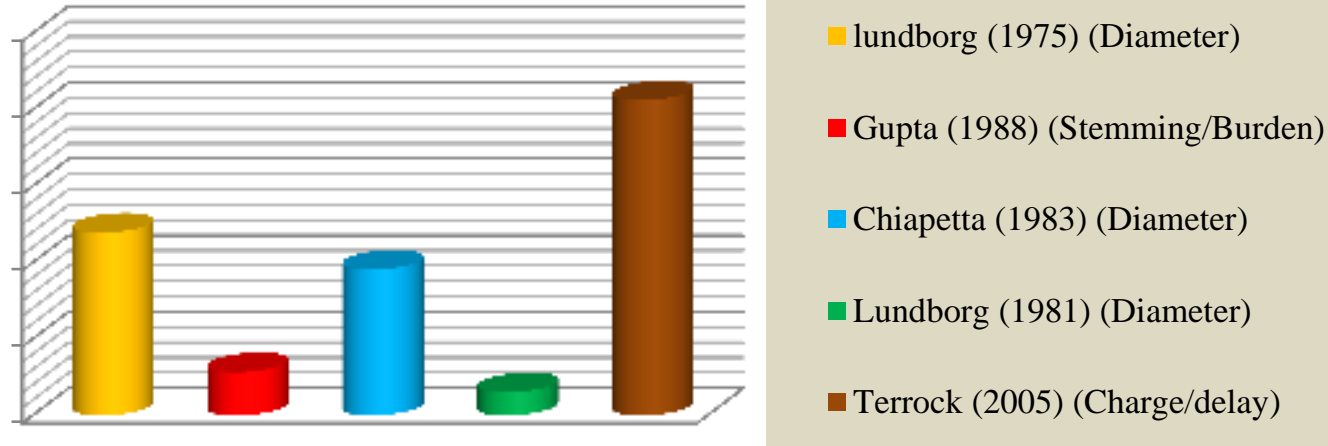

Figure 6. The results of maximum flyrock distances for Kyaukpahto Gold Mine

According to the results, Terrock equation (2005) is the maximum flyrock distance for the project. Lundborg equation (1981) is minimum flyrock distance for the project. In this paper, Terrock equation is used to predict the maximum flyrock distance for safety condition.

\section{RESULTS AND DISCUSSION}

In this paper, Terrock equation (2005) is used with the various burden distance and charge per delay to predict the maximum flyrock distance. Table 7 to 9 shows maximum flyrock distances for sandstone, dolomite and granite rock.

Table 7. Maximum flyrock distance for sandstone

\begin{tabular}{|c|c|c|c|c|c|c|c|c|c|c|}
\hline \multirow{2}{*}{$\begin{array}{c}\text { Burden } \\
(\mathrm{m})\end{array}$} & \multicolumn{9}{|c|}{ Charge per delay $(\mathrm{kg})$} \\
\cline { 2 - 11 } & 10 & 15 & 20 & 25 & 30 & 35 & 40 & 45 & 50 & 55 \\
\hline 1.5 & 219.0 & 371.1 & 539.3 & 720.8 & 913.7 & 1116.4 & 1328.0 & 1547.7 & 1774.9 & 2009.1 \\
\hline 1.6 & 201.4 & 341.2 & 495.9 & 662.8 & 840.1 & 1026.5 & 1221.1 & 1423.2 & 1632.1 & 1847.4 \\
\hline 1.7 & 186.1 & 315.3 & 458.3 & 612.6 & 776.5 & 948.7 & 1128.6 & 1315.3 & 1508.4 & 1707.4 \\
\hline 1.8 & 172.8 & 292.8 & 425.5 & 568.7 & 720.8 & 880.8 & 1047.8 & 1221.1 & 1400.4 & 1585.1 \\
\hline 1.8 & 161.1 & 272.9 & 396.6 & 530.1 & 671.9 & 821.0 & 976.7 & 1138.3 & 1305.3 & 1477.5 \\
\hline 1.9 & 150.7 & 255.3 & 371.1 & 495.9 & 628.6 & 768.1 & 913.7 & 1064.8 & 1221.1 & 1382.2 \\
\hline 2 & 141.4 & 239.6 & 348.3 & 465.5 & 589.9 & 720.8 & 857.5 & 999.4 & 1146.1 & 1297.3 \\
\hline 2.1 & 133.1 & 225.5 & 327.8 & 438.1 & 555.3 & 678.5 & 807.2 & 940.7 & 1078.8 & 1221.1 \\
\hline 2.2 & 125.7 & 212.9 & 309.4 & 413.5 & 524.1 & 640.4 & 761.9 & 887.9 & 1018.3 & 1152.6 \\
\hline 2.3 & 118.9 & 201.4 & 292.8 & 391.3 & 495.9 & 606.0 & 720.8 & 840.1 & 963.4 & 1090.5 \\
\hline 2.4 & 112.8 & 191.0 & 277.6 & 371.1 & 470.3 & 574.7 & 683.6 & 796.7 & 913.7 & 1034.2 \\
\hline 2.5 & 107.1 & 181.5 & 263.8 & 352.6 & 446.9 & 546.1 & 649.6 & 757.1 & 868.2 & 982.8 \\
\hline 2.6 & 102.0 & 172.8 & 251.2 & 335.7 & 425.5 & 519.9 & 618.5 & 720.8 & 826.7 & 935.7 \\
\hline 2.7 & 97.3 & 164.8 & 239.6 & 320.2 & 405.9 & 495.9 & 589.9 & 687.6 & 788.5 & 892.5 \\
\hline 2.8 & 93.0 & 157.5 & 228.9 & 305.9 & 387.8 & 473.8 & 563.6 & 656.9 & 753.3 & 852.7 \\
\hline
\end{tabular}


International Journal of Advances in Scientific Research and Engineering (ijasre), Vol 5 (10), October-2019

\begin{tabular}{|c|c|c|c|c|c|c|c|c|c|c|}
\hline 2.9 & 89.0 & 150.7 & 219.0 & 292.8 & 371.1 & 453.4 & 539.3 & 628.6 & 720.8 & 815.9 \\
\hline 3 & 85.2 & 144.4 & 209.9 & 280.5 & 355.6 & 434.5 & 516.8 & 602.3 & 690.8 & 781.9 \\
\hline 3.1 & 81.8 & 138.6 & 201.4 & 269.2 & 341.2 & 416.9 & 495.9 & 578.0 & 662.8 & 750.3 \\
\hline 3.2 & 78.6 & 133.1 & 193.5 & 258.6 & 327.8 & 400.6 & 476.5 & 555.3 & 636.8 & 720.8 \\
\hline 3.3 & 75.6 & 128.1 & 186.1 & 248.8 & 315.3 & 385.3 & 458.3 & 534.2 & 612.6 & 693.4 \\
\hline
\end{tabular}

Table 8. Maximum flyrock distance for dolomite

\begin{tabular}{|c|c|c|c|c|c|c|c|c|c|c|}
\hline \multirow{2}{*}{$\begin{array}{c}\text { Burden } \\
(\mathrm{m})\end{array}$} & \multicolumn{10}{|c|}{ Charge per delay $(\mathrm{kg})$} \\
\cline { 2 - 12 } & 10 & 15 & 20 & 25 & 30 & 35 & 40 & 45 & 50 & 55 \\
\hline 1.5 & 480.7 & 814.4 & 1183.7 & 1582.1 & 2005.3 & 2450.2 & 2914.7 & 3397.0 & 3895.6 & 4409.5 \\
\hline 1.6 & 442.1 & 748.9 & 1088.5 & 1454.8 & 1843.9 & 2253.0 & 2680.1 & 3123.6 & 3582.1 & 4054.6 \\
\hline 1.7 & 408.6 & 692.1 & 1006.0 & 1344.5 & 1704.2 & 2082.3 & 2477.0 & 2886.9 & 3310.6 & 3747.3 \\
\hline 1.8 & 379.3 & 642.5 & 933.9 & 1248.3 & 1582.1 & 1933.2 & 2299.6 & 2680.1 & 3073.6 & 3479.0 \\
\hline 1.8 & 353.6 & 598.9 & 870.5 & 1163.5 & 1474.7 & 1801.9 & 2143.5 & 2498.2 & 2864.9 & 3242.8 \\
\hline 1.9 & 330.7 & 560.3 & 814.4 & 1088.5 & 1379.6 & 1685.7 & 2005.3 & 2337.1 & 2680.1 & 3033.7 \\
\hline 2 & 310.4 & 525.9 & 764.3 & 1021.6 & 1294.8 & 1582.1 & 1882.0 & 2193.4 & 2515.4 & 2847.2 \\
\hline 2.1 & 292.2 & 495.0 & 719.5 & 961.6 & 1218.8 & 1489.3 & 1771.6 & 2064.7 & 2367.8 & 2680.1 \\
\hline 2.2 & 275.8 & 467.2 & 679.1 & 907.6 & 1150.4 & 1405.6 & 1672.1 & 1948.8 & 2234.9 & 2529.6 \\
\hline 2.3 & 261.0 & 442.1 & 642.5 & 858.8 & 1088.5 & 1330.0 & 1582.1 & 1843.9 & 2114.6 & 2393.5 \\
\hline 2.4 & 247.5 & 419.2 & 609.3 & 814.4 & 1032.2 & 1261.2 & 1500.3 & 1748.6 & 2005.3 & 2269.8 \\
\hline 2.5 & 235.2 & 398.4 & 579.0 & 773.9 & 980.9 & 1198.6 & 1425.8 & 1661.7 & 1905.6 & 2156.9 \\
\hline 2.6 & 223.9 & 379.3 & 551.3 & 736.9 & 933.9 & 1141.2 & 1357.5 & 1582.1 & 1814.4 & 2053.7 \\
\hline 2.7 & 213.6 & 361.8 & 525.9 & 702.8 & 890.8 & 1088.5 & 1294.8 & 1509.1 & 1730.6 & 1958.8 \\
\hline 2.8 & 204.0 & 345.6 & 502.4 & 671.5 & 851.1 & 1039.9 & 1237.1 & 1441.8 & 1653.4 & 1871.5 \\
\hline 2.9 & 195.2 & 330.7 & 480.7 & 642.5 & 814.4 & 995.1 & 1183.7 & 1379.6 & 1582.1 & 1790.8 \\
\hline 3 & 187.1 & 316.9 & 460.7 & 615.7 & 780.4 & 953.6 & 1134.3 & 1322.0 & 1516.1 & 1716.1 \\
\hline 3.1 & 179.5 & 304.1 & 442.1 & 590.8 & 748.9 & 915.0 & 1088.5 & 1268.6 & 1454.8 & 1646.7 \\
\hline 3.2 & 172.5 & 292.2 & 424.7 & 567.7 & 719.5 & 879.1 & 1045.8 & 1218.8 & 1397.7 & 1582.1 \\
\hline 3.3 & 165.9 & 281.1 & 408.6 & 546.1 & 692.1 & 845.7 & 1006.0 & 1172.4 & 1344.5 & 1521.9 \\
\hline
\end{tabular}

Table 9. Maximum flyrock distance for granite

\begin{tabular}{|c|c|c|c|c|c|c|c|c|c|c|c|}
\hline \multirow{2}{*}{$\begin{array}{c}\text { Burden } \\
(\mathrm{m})\end{array}$} & \multicolumn{10}{|c|}{ Charge per delay $(\mathrm{kg})$} \\
\cline { 2 - 11 } & 10 & 15 & 20 & 25 & 30 & 35 & 40 & 45 & 50 & 55 \\
\hline 1.5 & 876.2 & 1484.2 & 2157.4 & 2883.4 & 3654.6 & 4465.5 & 5312.0 & 6191.0 & 7099.8 & 8036.3 \\
\hline 1.6 & 805.6 & 1364.8 & 1983.7 & 2651.4 & 3360.5 & 4106.1 & 4884.5 & 5692.7 & 6528.4 & 7389.5 \\
\hline 1.7 & 744.6 & 1261.4 & 1833.4 & 2450.4 & 3105.8 & 3795.0 & 4514.4 & 5261.3 & 6033.6 & 6829.5 \\
\hline 1.8 & 691.3 & 1171.0 & 1702.1 & 2274.9 & 2883.4 & 3523.2 & 4191.1 & 4884.5 & 5601.5 & 6340.4 \\
\hline 1.8 & 644.3 & 1091.5 & 1586.6 & 2120.5 & 2687.7 & 3284.1 & 3906.6 & 4553.0 & 5221.3 & 5910.1 \\
\hline 1.9 & 602.8 & 1021.1 & 1484.2 & 1983.7 & 2514.3 & 3072.2 & 3654.6 & 4259.3 & 4884.5 & 5528.8 \\
\hline 2 & 565.7 & 958.4 & 1393.0 & 1861.8 & 2359.8 & 2883.4 & 3430.0 & 3997.5 & 4584.3 & 5189.1 \\
\hline 2.1 & 532.5 & 902.1 & 1311.3 & 1752.6 & 2221.3 & 2714.2 & 3228.7 & 3762.9 & 4315.3 & 4884.5 \\
\hline 2.2 & 502.6 & 851.5 & 1237.6 & 1654.2 & 2096.6 & 2561.8 & 3047.4 & 3551.7 & 4073.0 & 4610.3 \\
\hline 2.3 & 475.6 & 805.6 & 1171.0 & 1565.1 & 1983.7 & 2423.9 & 2883.4 & 3360.5 & 3853.8 & 4362.1 \\
\hline 2.4 & 451.0 & 764.0 & 1110.5 & 1484.2 & 1881.2 & 2298.6 & 2734.4 & 3186.8 & 3654.6 & 4136.7 \\
\hline 2.5 & 428.6 & 726.0 & 1055.3 & 1410.5 & 1787.7 & 2184.4 & 2598.4 & 3028.4 & 3472.9 & 3931.0 \\
\hline 2.6 & 408.1 & 691.3 & 1004.8 & 1342.9 & 1702.1 & 2079.8 & 2474.0 & 2883.4 & 3306.7 & 3742.8 \\
\hline 2.7 & 389.2 & 659.3 & 958.4 & 1280.9 & 1623.5 & 1983.7 & 2359.8 & 2750.3 & 3154.0 & 3570.0 \\
\hline 2.8 & 371.9 & 629.9 & 915.6 & 1223.8 & 1551.1 & 1895.3 & 2254.6 & 2627.6 & 3013.3 & 3410.8 \\
\hline 2.9 & 355.8 & 602.8 & 876.2 & 1171.0 & 1484.2 & 1813.6 & 2157.4 & 2514.3 & 2883.4 & 3263.7 \\
\hline 3 & 341.0 & 577.6 & 839.6 & 1122.2 & 1422.3 & 1737.9 & 2067.3 & 2409.4 & 2763.1 & 3127.5 \\
\hline 3.1 & 327.2 & 554.3 & 805.6 & 1076.8 & 1364.8 & 1667.6 & 1983.7 & 2312.0 & 2651.4 & 3001.1 \\
\hline 3.2 & 314.4 & 532.5 & 774.1 & 1034.6 & 1311.3 & 1602.2 & 1905.9 & 2221.3 & 2547.4 & 2883.4 \\
\hline 3.3 & 302.4 & 512.3 & 744.6 & 995.2 & 1261.4 & 1541.2 & 1833.4 & 2136.8 & 2450.4 & 2773.6 \\
\hline
\end{tabular}


International Journal of Advances in Scientific Research and Engineering (ijasre), Vol 5 (10), October-2019

\section{CONCLUSION}

The flyrock issue has been investigated by several researchers to predict the maximum travel distance of the flyrock fragment. Flyrock is always a major concern for the blaster. Flyrock from surface blasting operations has caused serious injury and death to employees and other persons. Moreover, flyrock can travel 3,000 feet or more, reach speeds of 400 miles per hour, and can penetrate buildings, smash vehicles, and cause great bodily harm. In this paper, empirical formula and excel program are used with the various burden distances and charge per delay to predict the maximum flyrock distances. Moreover, causes of flyrock are discussed to mitigate blasting accidents. Environmental constraints will be more and more restrictive on mining activities in Myanmar. So, measuring the flyrock distance induced by blasting is a significant step in order to control environmental problems.

\section{REFERENCES}

[1] A. D. Jahed, M. E. Tonnizan and Hajihassani, "Evaluation and Prediction of Flyrock Resulting from Blasting Operations using Empirical and Computational Methods," Verlag, London, 2015.

[2] A. K. Raina, V. M. S. R. Murthy and A. K. Soni, "Flyrocin Bench Blasting: A Comprehensive Review," Bull Eng Geol Environ, India, 2014.

[3] A. K. Mishra and M. Rout, " Flyrocks - Detection and Mitigation at Construction Site in Blasting Operation," Department of Mining Engineering, Indian School of Mines, Dhanbad, 2011.

[4] G. R. Tripathy and I. D. Gupta, "Technical Note on the Prediction and Control of Flyrock during Rock Blasting," J. of Rock Mechanics and Tunneling Tech. 142 Vol.10 No.2. India, 2002.

[5] J. M. Adrian, and B. R. Alan, "Golden Pike Cut-Back Flyrock Control and Calibration of a Predictive Model," Terrock, 2005.

[6] N. Amegbey, and B. O. Afum, "Blast Impact Prediction Studies at Ghana Manganese Company (GMC) Limited," Nsuta, Ghana, Vol. 15 No. 1, June, 2015.

\section{AUTHORS}

First Author - Myo Min Lwin, Professor, Mandalay Technological University and sayarmyo02@gmail.com

Second Author - Zaw Moon Aung, Demonstrator, Mandalay Technological University and zawmoonaung2017@gmail.com

Correspondence Author - Myo Min Lwin, Professor, Mandalay Technological University, sayarmyo02@ gmail.com 